\title{
P032. Coenzyme Q-10 and migraine: a lovable relationship. The experience of a tertiary headache center
}

\author{
Ennio Pucci ${ }^{1,2,3^{*}}$, Luca Diamanti ${ }^{1,2}$, Silvano Cristina ${ }^{1,2}$, Fabio Antonaci ${ }^{1,2,3}$, Alfredo Costa ${ }^{1,2,3}$ \\ From Abstracts from the 1st Joint ANIRCEF-SISC Congress \\ Rome, Italy. 29-31 October 2015
}

\section{Background}

Coenzyme Q-10 (ubiquinone) is a small hydrophobic substance that acts as an electron carrier in the mitochondrial respiratory chain. Its main activity is to protect DNA, proteins and lipids from oxidative stress. In the literature, a role of brain oxidative metabolism in the pathogenesis of migraine has been hypothesized [1]. Few clinical trials are described using coenzyme Q-10 in migraine prophylaxis, even in pediatrics [2-4]. The aim of this work was to present our experience of migraine prevention, prescribing coenzyme Q-10 to 20 adult patients with migraine without aura.

\section{Materials and methods}

Patients were enrolled in a tertiary headache center and followed for a period of 60 days (visit 1 and visit 2). The dose of coenzyme Q-10 was $200 \mathrm{mg} /$ day. Visual analogue scale (VAS) was used to measure pain.

\section{Results}

In our cohort, male/female ratio was $1: 5$, while the mean age was 32.1 years (range, 22-49 years). Patients had a relatively short history of disease (mean 5.6 years; range 2-18), indeed only 2 of them were on a first-line treatment whereas coenzyme Q-10 was the starting therapy for others. We noticed a significant reduction of the number of crises at visit 2 (mean 3.15 vs $0.9, \mathrm{p}<$ 0.05 ), as well as VAS score (mean 6.65 vs $1.45, \mathrm{p}<0.05$ ) and monthly days of headache (mean 6.3 vs $1.5, \mathrm{p}<$ 0.05). No one showed side effects, body weight did not vary (mean 56.55 vs mean 56.65 ) and patients did not even experience drastic weight loss or gain. The drug was well tolerated with a mean satisfaction score of 7.65 (range, 0-10). Moreover, patients reported positive effects on fatigue.

\section{Conclusions}

Coenzyme Q-10 is a safe and effective therapy for migraine prophylaxis.

Written informed consent to publish was obtained from the patient(s).

\section{Conflict of interest}

None. This study did not receive any industry funding.

\section{Authors' details}

'Department of Brain and Behavioral Sciences, University of Pavia, Pavia, Italy. ${ }^{2}$ IRCCS National Neurological Institute, "C. Mondino", Pavia, Italy. ${ }^{3}$ Headache Science Center, University Consortium for the Study of Adaptive Disorders and Headache (UCADH), Pavia, Italy.

\section{Published: 28 September 2015}

\section{References}

1. Montagna P, Sacquegna T, Cortelli P, Lugaresi E: Migraine as a defect of brain oxidative metabolism: a hypothesis. J Neurol 1989, 236(2):124-125.

2. Slater SK, Nelson TD, Kabbouche MA, LeCates SL, Horn P, Segers A, et al: A randomized, double-blinded, placebo-controlled, crossover, add-on study of CoEnzyme Q10 in the prevention of pediatric and adolescent migraine. Cephalalgia 2011, 31(8):897-905.

3. Sándor PS, Di Clemente L, Coppola G, Saenger U, Fumal A, Magis D, et al: Efficacy of coenzyme Q10 in migraine prophylaxis: a randomized controlled trial. Neurology 2005, 64(4):713-715.

4. Rozen TD, Oshinsky ML, Gebeline CA, Bradley KC, Young WB, Shechter AL, Silberstein SD: Open label trial of coenzyme Q10 as a migraine preventive. Cephalalgia 2002, 22(2):137-141.

doi:10.1186/1129-2377-16-S1-A139

Cite this article as: Pucci et al:: P032. Coenzyme Q-10 and migraine: a lovable relationship. The experience of a tertiary headache center. The Journal of Headache and Pain 2015 16(Suppl 1):A139.

\footnotetext{
* Correspondence: ennio.pucci@mondino.it

'Department of Brain and Behavioral Sciences, University of Pavia, Pavia, Italy

Full list of author information is available at the end of the article
} 